\title{
Estimação da profundidade de fissuras em concreto através da velocidade de ondas ultrassônicas
}

\section{Estimation of the depth of cracks in concrete through the velocity of ultrasonic waves}

\author{
Marcela Tavares de Araújo Silva ${ }^{1}$, Joaquin Humberto Aquino Rocha ${ }^{2}$, \\ Eliana Cristina Barreto Monteiro ${ }^{1,3}$
}

\footnotetext{
${ }^{1}$ Universidade de Pernambuco (UPE), Escola Politécnica de Pernambuco (POLI-UPE), Programa de Pós-Graduação em Engenharia Civil (PEC-POLI), Rua Benfica, n. 455, CEP 50720-001, Madalena, Recife-PE, Brasil.

${ }^{2}$ Universidad Privada del Valle (UNIVALLE), Cochabamba, Cercado, Bolívia.

${ }^{3}$ Universidade Católica de Pernambuco (UNICAP), Boa Vista, Recife-PE, Brasil.

e-mail:mtas_pec@poli.br,jaquinor@univalle.edu,eliana@poli.br
}

\begin{abstract}
RESUMO
As fissuras são as manifestações patológicas mais recorrentes no concreto, devido as diferentes formas de exposição que o material está sujeito. Neste cenário, é importante que as edificações passem por inspeções através de diferentes métodos, dentre os quais os ensaios não destrutivos (END) aparecem como ferramenta alternativa. Dentre os END, o ensaio de velocidade de propagação de ondas ultrassônicas, conhecido como Ultrassom, foi utilizado neste estudo. A utilização do Ultrassom teve por objetivo avaliar a aplicação do método em prismas de concreto para estimar a profundidade de fissuras, utilizando um modelo matemático existente na literatura. Também foi avaliado a influência da distância de execução do ensaio. Os resultados encontrados foram comparados com as profundidades reais simuladas nos prismas de concreto, utilizando uma análise estatística. Diante dos resultados percebeu-se que o ensaio de ultrassom é eficaz para detectar a presença de fissuras, pois ela altera o tempo de propagação da onda. O modelo matemático testado, com a utilização do ultrassom, conseguiu estimar em $88.5 \%$ dos casos a profundidade das fissuras, porém com resultados bastante dispersos e alta margem de erro, inviabilizando sua aplicação em estruturas reais. Concluiu-se que as distâncias de execução de até $20 \mathrm{~cm}$ apresentaram melhores resultados.
\end{abstract}

Palavras-chave: Ultrassom. Fissuras. Profundidade. Concreto.

\begin{abstract}
Cracks are the most recurrent pathological manifestations in concrete, due to the different forms of exposure that the material is subject to. In this scenario, it is important that buildings undergo inspections through different methods, among which non-destructive testing (NDT) appear as an alternative tool. Among the NDTs, the ultrasonic wave propagation velocity test, known as Ultrasound, was used in this study. The purpose of this study was to evaluate the application of the method in concrete prisms to estimate the depth of cracks using a mathematical model in the literature. The influence of the test distance was also evaluated. The results were compared with the depths simulated in the concrete prisms, using a statistical analysis. It was noticed that the ultrasound test is effective to detect the presence of cracks, as it changes the propagation time of the wave. The mathematical model tested, with the use of ultrasound, was able to estimate the depth of the cracks in $88.5 \%$ of cases, but with very dispersed results and a high margin of error, making it impossible to apply them to real structures. It was concluded that the distances of execution of up to $20 \mathrm{~cm}$ presented better results.
\end{abstract}

Keywords: Ultrasound. Fissures. Depth. Concrete.

\section{INTRODUÇÃO}

O concreto é um dos materiais mais utilizados na indústria da construção civil, devido à facilidade de aquisi- 
ção dos materiais constituintes, à simplicidade de execução e à difundida técnica de produção. No Brasil, a produção é elevada chegando a 51 milhões de $\mathrm{m}^{3} / \mathrm{ano}$, valor oriundo das concreteiras [1]. A utilização do concreto pode ser observada desde obras simples até as mais complexas, como edifícios, obras de infraestruturas, pontes, viadutos e barragens. Diante deste cenário, têm-se estruturas de qualidades diferentes expostas a ambientes com variadas formas de agressividade, as quais podem ocasionar a deterioração das estruturas, tendo como consequências as manifestações patológicas.

A ocorrência de fissuras está entre as manifestações patológicas mais recorrentes nas estruturas de concreto. As causas das fissuras são diversas, podendo estas serem intrínsecas - tendo como exemplos as resultantes de retração plástica, deficiência de projeto e execução, retração térmica e assentamento plástico do concreto, bem como as ocasionadas pela movimentação de fôrmas e escoramentos - ou extrínsecas, devidas ao assentamento de apoios e fundações, variações térmicas, sobrecargas, corrosão das armaduras, reação álcali-agregado e ataque por sulfatos [2]. Para SILVA FILHO e HELENE [3], problemas de resistência e perda da integridade por fissuração são patologias que necessitam ser tratadas e diagnosticadas antecipadamente, pois podem afetar a segurança, durabilidade e funcionalidade das estruturas.

Neste contexto, cada vez mais ressalta-se a importância da inspeção periódicas nas construções, a fim de verificar pontos danificados e, com isto, realizar nesses locais ensaios mais detalhados que possam fornecer informações acerca dos parâmetros dos danos [4].

Diversas técnicas de monitoramento de estruturas estão disponíveis no mercado, dentre elas encontram-se os ensaios não destrutivos (END). Eles têm como principal característica a possibilidade de obtenção de informações acerca do concreto no estado endurecido sem a necessidade de danificar a estrutura [2,5]. As técnicas de END mais utilizadas na inspeção de estruturas de concreto são: a ultrassonografia, a termografia, a pacometria, o radar e a esclerometria.

A termografia é uma técnica utilizada para detecção de defeitos e avaliação da heterogeneidade do concreto [4]. A pacometria é útil para o mapeamento das estruturas, pois através dela é possível localizar armaduras, diâmetro e espessura do cobrimento do concreto [6]. Segundo LORENZI et al. [5], a técnica do radar é eficiente para determinação de descontinuidades no concreto. A esclerometria visa medir a dureza superficial do concreto, permitindo avaliar sua qualidade quando endurecido [2,7].

A técnica de ultrassom se baseia na propagação de ondas ultrassônicas através do material, onde, com a utilização de um transdutor emissor e outro receptor, a onda percorre o material e, ao final, sua velocidade é obtida através do tempo resultante para percorrer uma distância conhecida [8]. De acordo com PACHECO et al. [9], através da utilização do ultrassom é possível obter o módulo de elasticidade e massa específica do concreto. Já MENEZES et al. [10] afirmam que o ensaio também pode ser utilizado para localizar e dimensionar descontinuidades na estrutura.

Diversos trabalhos confirmam a possibilidade de se estimar profundidades de fissuras através do tempo de propagação de ondas ultrassônicas [11-13]; no entanto, existem muitos fatores que influenciam os resultados como: distância de execução do ensaio, a profundidade da fissura, do operador, da qualidade de concreto, dentre outros. Neste sentido, o presente artigo tem como objetivo avaliar a eficácia do método de ultrassom para estimação da profundidade de fissuras em estruturas de concreto e a influência do parâmetro da distância de execução do ensaio nos resultados.

\section{MATERIAIS E MÉTODOS}

Para atender os objetivos desta pesquisa, foram moldados 12 prismas de concreto com fissuras induzidas a fim de estimar a profundidade das mesmas, através da utilização do modelo matemático proposto por BUNGEY et al. [11]. Foram utilizadas três diferentes profundidades de fissuras $(5 \mathrm{~cm}, 10 \mathrm{~cm}$ e $15 \mathrm{~cm})$ e quatro distâncias entre os transdutores para realização do ensaio $(10 \mathrm{~cm}, 20 \mathrm{~cm}, 30 \mathrm{~cm}$ e $40 \mathrm{~cm})$, de forma a avaliar a influência destas nos resultados encontrados.

Para facilitar a análise dos resultados, os prismas foram divididos em 3 grupos (séries) de acordo com a profundidade da fissura: Série I - prismas com $5 \mathrm{~cm}$ de profundidade; Série II - prismas com $10 \mathrm{~cm}$ de profundidades; e Série III - prismas com $15 \mathrm{~cm}$ de profundidade.

$\mathrm{O}$ equipamento de ultrassom utilizado neste trabalho foi o modelo 58-E4800 UPV, que vem equipado com dois transdutores com 50mm de diâmetro e frequência padrão de $54 \mathrm{KHz}$. A frequência dos transdutores pode ser alterada com aquisição de outros transdutores na faixa de 24 a $150 \mathrm{KHz}$. A taxa de pulso é selecionável podendo ser de 1, 2, 5 ou 10 pulsos por segundo [14]. 


\subsection{Corpos de prova}

Foram moldados prismas de concreto com dimensão de $20 \times 20 \times 50 \mathrm{~cm}$, e, no eixo dos mesmos, induzida uma fissura através da colocação de uma chapa metálica (espessura $0,95 \mathrm{~mm}$ ), que foi retirada antes do concreto endurecer. Para cada profundidade proposta $(5 \mathrm{~cm}, 10 \mathrm{~cm}$ e $15 \mathrm{~cm})$ foram confeccionados 4 prismas, totalizando 12 unidades. A Figura 1 mostra o detalhe dos prismas de concreto.
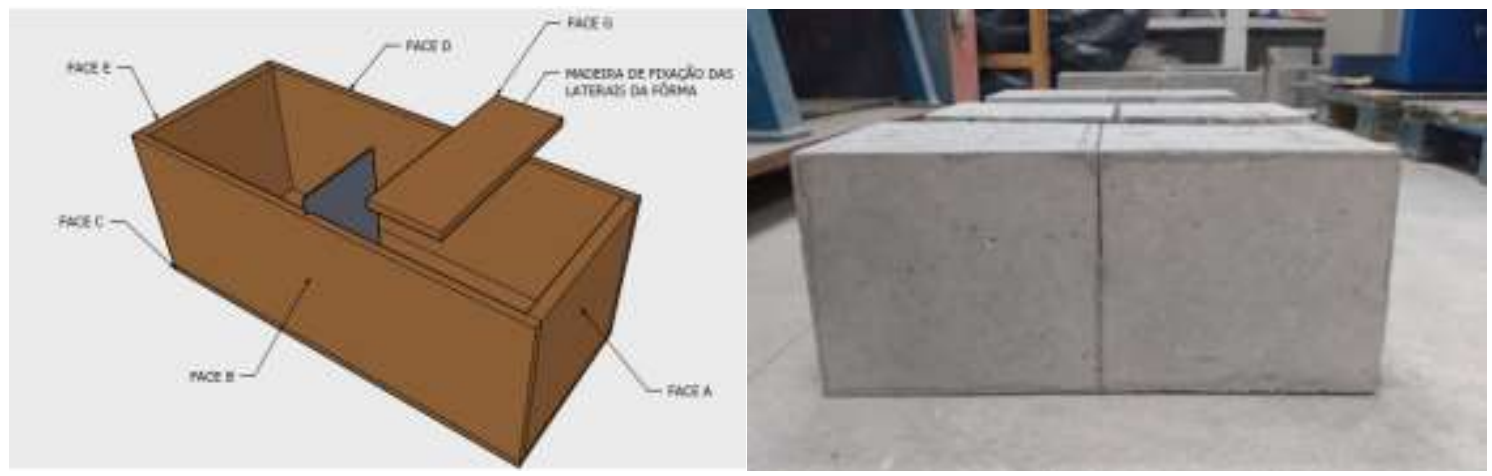

Figura 1: Detalhe dos prismas de concreto.

Os prismas foram produzidos com concreto dosado com relação água/cimento de 0,5. O traço utilizado foi de 1:1,46:2,51 (Cimento: Brita: Areia). O cimento utilizado foi o CPII Z-32 correspondente ao Pozzolan-Modified Portland da norma C 595 [15]. A distribuição granulométrica da brita e da areia atendeu aos limites indicados na norma NBR 7211 [16] de agregados para concreto. O diâmetro máximo da brita utilizada foi de $19 \mathrm{~mm}$.

Como os resultados forma analisados utilizando a estatística, é fundamental a definição do tamanho da amostra, de forma que a quantidade de prismas utilizados no estudo seja representativa. De acordo com HAIR et al. [17], em uma análise estatística o tamanho da amostra afeta a generalização dos resultados, pela relação entre as observações e as variáveis independentes. Uma regra geral é que a razão jamais deve ficar abaixo de 5 para 1, o que significa que deve haver cinco observações para cada variável independente na variável estatística. Apesar da proporção mínima ser de 5 para 1, o nível desejado está entre 15 e 20 observações para cada variável independente. Quando esse nível é alcançado, os resultados devem ser generalizáveis e a amostra considerada representativa.

Dessa forma, considerando as duas variáveis que estão presentes neste estudo, multiplicadas por quinze observações, tem-se que a quantidade mínima de trinta unidades amostrais. Para o presente estudo, foram confeccionados quatro prismas para cada Série. Como as profundidades eram em três medidas diferentes, os ensaios foram efetuados a quatro distâncias distintas e realizado duas vezes. Foram realizadas, no total, noventa e seis observações (quatro prismas x três profundidades x quatro distâncias x duas Repetições), valor superior ao mínimo desejável.

\subsection{Modelo matemático}

O modelo matemático proposto por BUNGEY et al. [11] afirma que é possível estimar a profundidade de fissuras perpendiculares à superfície de concreto através do modo de transmissão indireto. Para o modelo, os transdutores são colocados equidistantes da fissura, conforme apresentado na Figura 2.
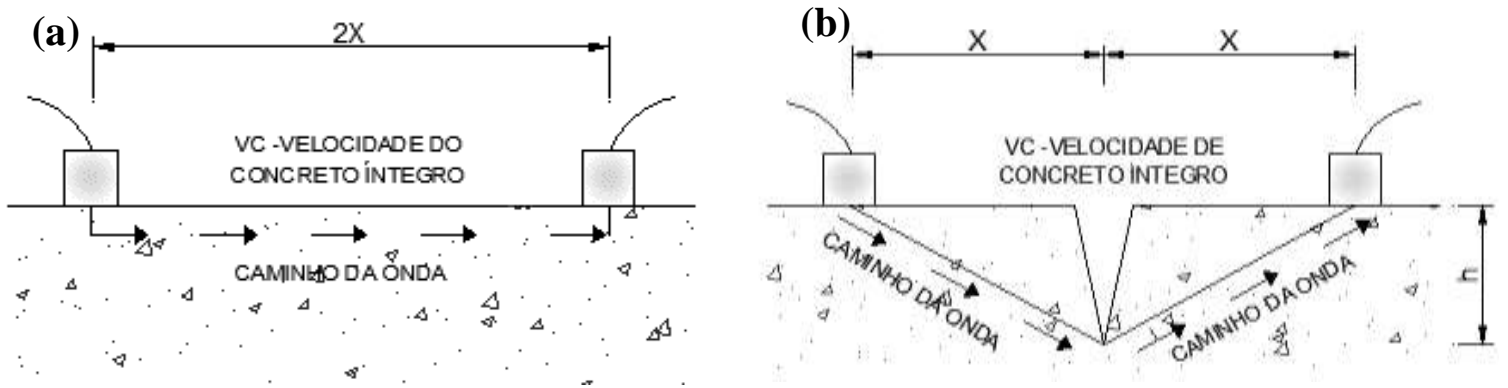

Figura 2: (a) Percurso da onda no concreto íntegro, (b) Percurso da onda ao redor da fissura. 
De acordo com este modelo, adota-se como "Vc" a velocidade da onda ultrassônica no concreto íntegro pelo método indireto como sendo a mesma velocidade no percurso em volta da fissura. Ou seja, se em uma região sem fissura for realizada uma leitura no modo indireto a uma distância $\mathrm{Y}=2 \mathrm{X}$ entre os transdutores (Figura 2a), encontra-se uma velocidade "Vc", partindo da premissa que a onda se desviará da fissura e que a velocidade se manterá a mesma por se tratar do mesmo material. Ao realizar a leitura na região fissurada com a distância " $X$ " do eixo da fissura ao transdutor (Figura 2b), pode-se estimar a profundidade da fissura. Desta forma, para o modelo, a diferença entre os dois percursos se dará no tempo de propagação, já que a velocidade será a mesma.

A premissa do modelo, a qual afirma que onda se desviará, tem base no conceito de onda mecânica, a qual necessita de um meio para se propagar.

Lc - Percurso sem a fissura, definido pela Equação 1.

$$
L c=2 x
$$

Lf - Percurso desviando a fissura, definido pela Equação 2.

$$
L f=2 \sqrt{x^{2}+h^{2}}
$$

Tc - tempo de propagação de onda no concreto íntegro, definido pela Equação 3.

$$
T c=\frac{2 x}{V c}
$$

Tf - tempo de propagação ao redor da fissura, definido pela Equação 4.

$$
T f=\frac{2 \sqrt{x^{2}+h^{2}}}{V c}
$$

Como "Vc" representa a mesma velocidade em ambos os casos, realizando a substituição na Equação 3 e 4, tem-se a Equação 5.

$$
h=x \sqrt{\frac{T f^{2}}{T c^{2}}-1}
$$

Onde $\mathrm{h}$ - Profundidade da fissura estimada pelo modelo $(\mathrm{cm})$ e $\mathrm{x}$ - Distância do eixo do transdutor ao eixo da fissura $(\mathrm{cm})$.

\subsection{Execução do ensaio}

A execução do ensaio de ultrassom foi realizada no modo indireto e seguindo as recomendações da NM-58 [18], onde determina que a superfície deve ser mantida lisa, evitando-se rugosidades.

Inicialmente, foi realizada a calibração do equipamento, conforme descreve o manual. Em seguida foram realizadas as marcações da malha de medição para realização do ensaio de ultrassom, composta por duas linhas, uma superior e outra inferior ao eixo horizontal da peça.

A partir do eixo da fissura, também foram marcadas linhas a cada $5 \mathrm{~cm}$, conforme apresentado na Figura 3, formando a malha de leitura para execução do ensaio. Em todos os pontos foram aplicados a vaselina para o acoplamento do transdutor com a superfície. 


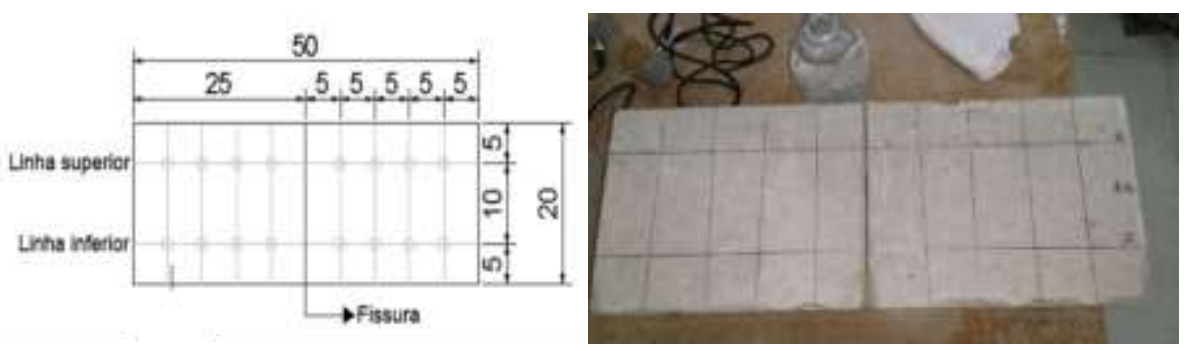

Figura 3: Esquema da marcação do ensaio.

Para cada ponto marcado, foram realizadas duas leituras de tempo de propagação da onda pelo modo indireto. Foram consideradas as médias dos tempos entre a linha superior e inferior. Em seguida, foi considerada para os cálculos a média dos dois tempos de leituras.

A velocidade de propagação das ondas ultrassônicas que passaram pelo concreto foi calculada através da Equação 6.

$$
V=\frac{L}{\Delta t}
$$

Onde V - Velocidade da onda (m/s); L - Distância entre os tradutores (m); e, $\Delta \mathrm{t}$ - Variação do tempo para a distância percorrida (s)

A obtenção da velocidade da onda pelo modo indireto é tratada na NBR 8802 [19] de maneira especial, onde o transdutor emissor é fixado e o transdutor receptor é deslocado com distâncias pré-determinadas. Com as leituras dos tempos de propagação para cada distância pré-determinada, plota-se o gráfico de tempo versus distância, e, a partir destes pontos, é traçada a reta que melhor se ajusta aos mesmos, onde a velocidade pelo modo indireto é obtida pela inclinação da reta, ou seja, a tangente da reta.

Para a aplicação do modelo matemático proposto por BUNGEY et al. [11], faz-se necessário a obtenção do tempo de propagação da onda pelo modo indireto no concreto íntegro - Tc. Esses valores devem ser obtidos nas mesmas distâncias que serão obtidos os tempos na região de fissura - Tf. Como a fissura foi induzida no meio do prisma, a região íntegra para obtenção do Tc foi a metade dele. Desta forma o transdutor emissor foi fixado na primeira marcação e o transdutor receptor foi deslocado a cada $5 \mathrm{~cm}$, obtendo-se a leitura dos tempos para as distâncias entre os transdutores $Y=5 \mathrm{~cm}, 10 \mathrm{~cm}$ e $15 \mathrm{~cm}$, conforme Figura 4 (a), (b) e (c). Onde E - Transdutor emissor; R - Transdutor receptor; e, Y - Distância entre os transdutores (cm).
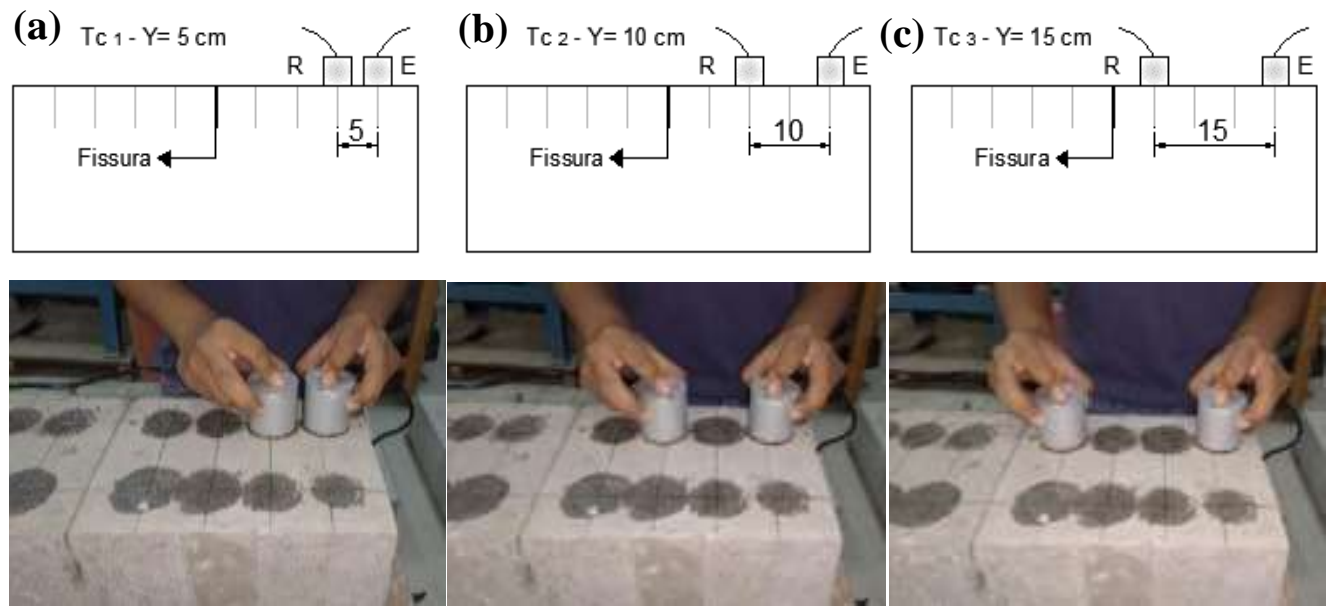

Figura 4: Leituras do tempo no concreto íntegro - Tc com transdutores distanciados a: (a) $5 \mathrm{~cm}$; (b) $10 \mathrm{~cm}$; (c) $15 \mathrm{~cm}$.

A partir das três leituras, foi plotado o gráfico da distância $(\mathrm{cm})$ versus tempo $(\mu \mathrm{s})$, para obtenção da reta que melhor se ajusta aos pontos (Figura 5) e, desta forma, encontrar os tempos de propagação de ondas no concreto íntegro ajustados pela reta - Tc' para as medidas de distâncias necessárias para aplicação da fórmula, $Y=10 \mathrm{~cm}, 20 \mathrm{~cm}, 30 \mathrm{~cm}$ e $40 \mathrm{~cm}$, como mostrada na Tabela 1, para o caso da primeira repetição do 
primeiro prisma da Série I. A identificação das medições está inicialmente pelo número de prisma (1, 2, 3 e 4) da série, seguido da profundidade $(\mathrm{P} 5=5 \mathrm{~cm}, \mathrm{P} 10=10 \mathrm{~cm}$ e $\mathrm{P} 15=15 \mathrm{~cm})$ e finalmente pela repetição $(-1$ para a primeira e -2 para a segunda).

Os tempos ajustados - Tc' foram encontrados para as distâncias $Y=10 \mathrm{~cm}, 20 \mathrm{~cm}, 30 \mathrm{~cm}$ e $40 \mathrm{~cm}$, sendo $\mathrm{Y}=2 \mathrm{X}$, onde $\mathrm{X}$ é a distância entre o eixo da fissura e o transdutor.

Para a medição do tempo de propagação da onda ao redor da fissura - Tf, foram realizadas as leituras pelo modo indireto com as distâncias entre os transdutores $Y=10 \mathrm{~cm}, 20 \mathrm{~cm}, 30 \mathrm{~cm}$ e $40 \mathrm{~cm}$, conforme Figura 6 (a) (b) (c) (d).

Com os resultados dos dois tempos Tc' e Tf para as mesmas distâncias X, entre o eixo da fissura e o transdutor, pode-se estimar a profundidade da fissura aplicando o modelo proposto por BUNGEY et al. [11].

O mesmo procedimento, para obtenção do Tc' e do Tf, foi repetido para todas as 3 séries, nas 4 réplicas dos prismas de concreto de cada série e para cada uma das duas repetições.

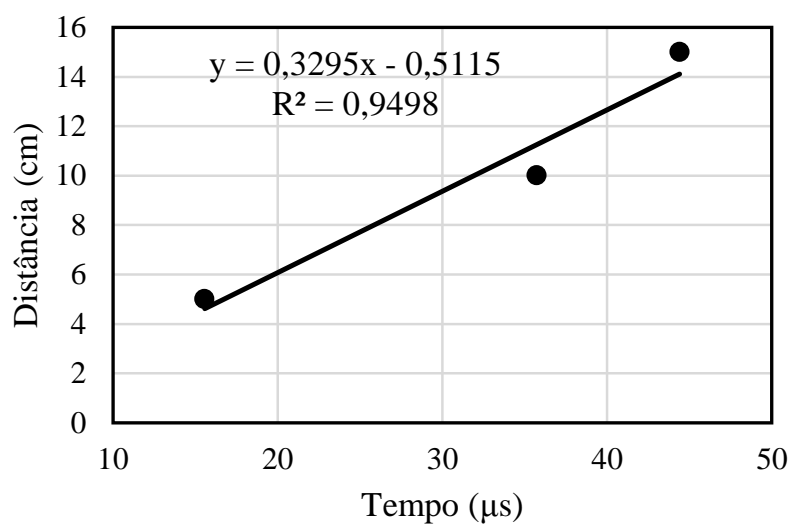

Figura 5: Gráfico distância x tempo (Série I - prisma 1).

Tabela 1: Tc' (Série I - Prisma 1 - Primeira repetição).

\begin{tabular}{|c|c|c|c|}
\hline IDENTIFICAÇÃO & Tc $(\mu \mathrm{s})$ & $Y(\mathrm{~cm})$ & Tc' ( $\mu \mathrm{s})$ \\
\hline 1P5-1 & 15,58 & 5,00 & 16,73 \\
\hline 1P5-1 & 35,73 & 10,00 & 31,90 \\
\hline 1P5-1 & 44,40 & 15,00 & 47,07 \\
\hline 1P5-1 & - & 20,00 & 62,25 \\
\hline 1P5-1 & - & 30,00 & 92,60 \\
\hline 1P5-1 & - & 40,00 & 122,94 \\
\hline \multicolumn{3}{|c|}{$\begin{array}{r}\text { Equação Linear } \\
\text { Intercepcão }\end{array}$} & $\begin{array}{c}\mathrm{Y}=0,3295 \mathrm{X}-0,5115 \\
-0,5115 \\
0,3295\end{array}$ \\
\hline
\end{tabular}



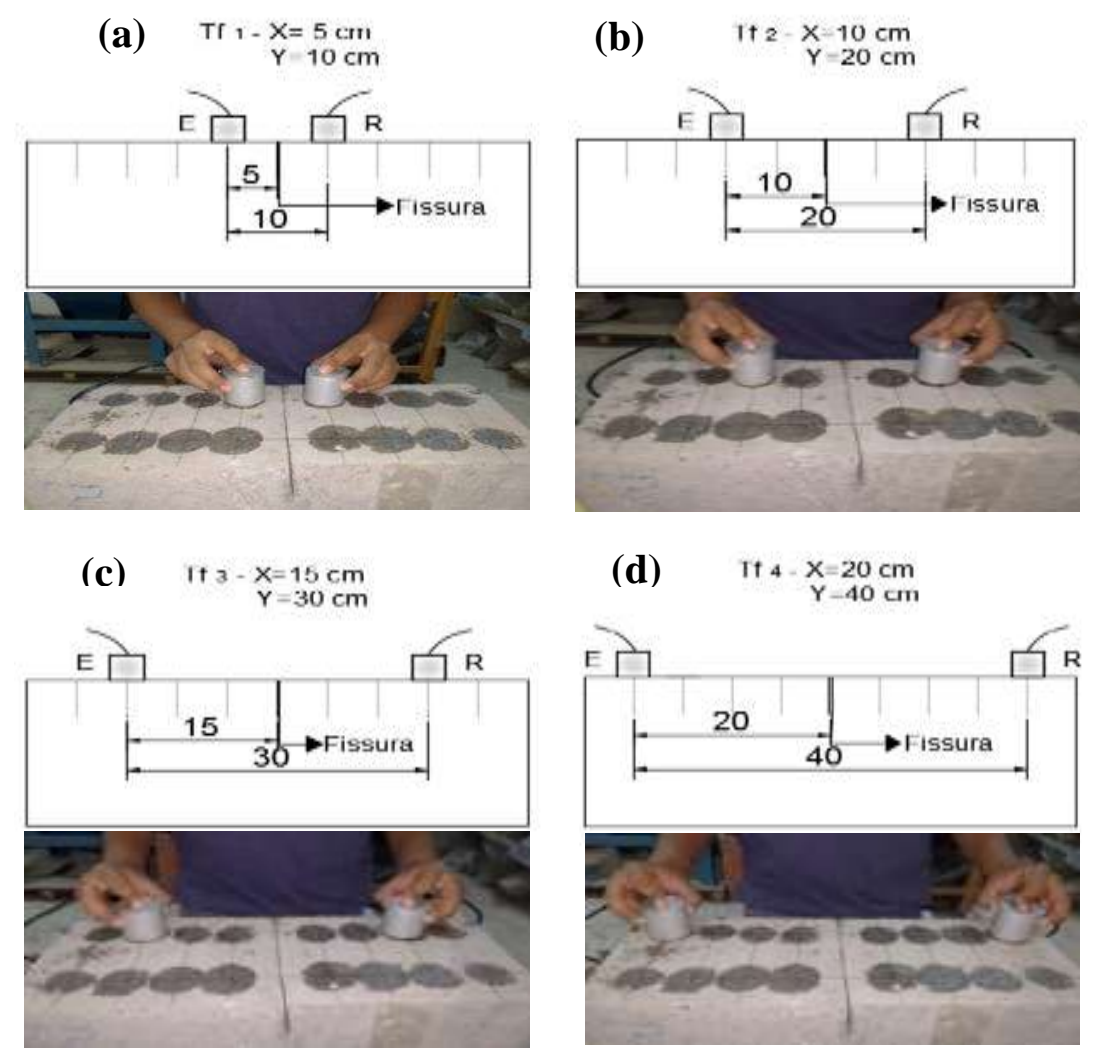

Figura 6: Leituras ao redor da fissura com transdutores distanciados a: (a) $10 \mathrm{~cm}$; (b) $20 \mathrm{~cm}$; (c) $30 \mathrm{~cm}$; (d) $40 \mathrm{~cm}$.

\section{RESULTADOS}

A Tabela 2 apresenta os resultados das profundidades das fissuras (h') agrupados por série e distância de execução do ensaio.

Tabela 2: Resultados da profundidade de fissuras separados por Série x distância.

PROFUNDIDADE DA FISSURA $h^{\prime}(\mathrm{cm})$

\begin{tabular}{|c|c|c|c|c|c|c|c|c|}
\hline \multirow[t]{2}{*}{ DISTÂNCIA } & \multicolumn{2}{|c|}{$10 \mathrm{~cm}$} & \multicolumn{2}{|c|}{$20 \mathrm{~cm}$} & \multicolumn{2}{|c|}{$30 \mathrm{~cm}$} & \multicolumn{2}{|c|}{$40 \mathrm{~cm}$} \\
\hline & Identificação & $h^{\prime}$ & Identificação & $h^{\prime}$ & Identificação & $h^{\prime}$ & Identificação & $h^{\prime}$ \\
\hline \multirow{8}{*}{ Série I } & $1 \mathrm{P} 5-1$ & 5,68 & 1P5-1 & 6,34 & 1P5-1 & 11,20 & 1P5-1 & 11,15 \\
\hline & $2 \mathrm{P} 5-1$ & 3,82 & $2 \mathrm{P} 5-1$ & 4,00 & $2 \mathrm{P} 5-1$ & 7,35 & $2 \mathrm{P} 5-1$ & 3,12 \\
\hline & 3P5-1 & 4,43 & 3P5-1 & 3,08 & 3P5-1 & 9,13 & 3P5-1 & 14,97 \\
\hline & 4P5-1 & 3,32 & 4P5-1 & 4,05 & 4P5-1 & 3,20 & 4P5-1 & 10,62 \\
\hline & 1P5-2 & 4,82 & 1P5-2 & 3,74 & 1P5-2 & 15,17 & 1P5-2 & 15,21 \\
\hline & $2 \mathrm{P} 5-2$ & 3,08 & $2 \mathrm{P} 5-2$ & $*$ & $2 \mathrm{P} 5-2$ & 5,88 & $2 \mathrm{P} 5-2$ & 9,00 \\
\hline & $3 P 5-2$ & 4,70 & $3 P 5-2$ & 3,93 & $3 P 5-2$ & 9,04 & $3 \mathrm{P} 5-2$ & 10,59 \\
\hline & $4 \mathrm{P} 5-2$ & 2,67 & $4 \mathrm{P} 5-2$ & $*$ & $4 \mathrm{P} 5-2$ & 6,48 & $4 \mathrm{P} 5-2$ & 8,94 \\
\hline \multirow{8}{*}{ Série II } & 1P10-1 & 6,71 & 1P10-1 & 9,82 & 1P10-1 & 11,22 & 1P10-1 & 9,78 \\
\hline & 2P10-1 & 6,05 & 2P10-1 & 7,15 & 2P10-1 & $*$ & 2P10-1 & $*$ \\
\hline & 3P10-1 & 5,63 & 3P10-1 & 7,74 & 3P10-1 & 6,64 & 3P10-1 & 11,60 \\
\hline & 4VP10-1 & 6,22 & $4 \mathrm{P} 10-1$ & 8,70 & 4P10-1 & 5,11 & 4P10-1 & 7,35 \\
\hline & 1P10-2 & 6,38 & 1P10-2 & 4,96 & 1P10-2 & $*$ & 1P10-2 & $*$ \\
\hline & $2 \mathrm{P} 10-2$ & 7,01 & $2 \mathrm{P} 10-2$ & 5,98 & $2 \mathrm{P} 10-2$ & $*$ & $2 \mathrm{P} 10-2$ & $*$ \\
\hline & 3P10-2 & 6,58 & 3P10-2 & 5,27 & $3 \mathrm{P} 10-2$ & $*$ & $3 \mathrm{P} 10-2$ & $*$ \\
\hline & 4P10-2 & 8,19 & 4P10-2 & 9,54 & 4P10-2 & 7,61 & 4P10-2 & 4,17 \\
\hline \multirow{2}{*}{ Série III } & 1P15-1 & 10,43 & 1P15-1 & 12,27 & 1P15-1 & 10,51 & 1P15-1 & 7,23 \\
\hline & 2P15-1 & 24,40 & 2P15-1 & 19,57 & 2P15-1 & 24,56 & $2 \mathrm{P} 15-1$ & 21,86 \\
\hline
\end{tabular}




\begin{tabular}{|l|c|l|c|l|l|l|c}
$3 \mathrm{P} 15-1$ & 11,10 & $3 \mathrm{P} 15-1$ & 15,79 & $3 \mathrm{P} 15-1$ & 14,64 & $3 \mathrm{P} 15-1$ & 11,08 \\
$4 \mathrm{P} 15-1$ & 9,56 & $4 \mathrm{P} 15-1$ & 9,19 & $4 \mathrm{P} 15-1$ & 5,92 & $4 \mathrm{P} 15-1$ & $*$ \\
$1 \mathrm{P} 15-2$ & 12,21 & $1 \mathrm{P} 15-2$ & 14,95 & $1 \mathrm{P} 15-2$ & 10,25 & $1 \mathrm{P} 15-2$ & 7,94 \\
$2 \mathrm{P} 15-2$ & 25,73 & $2 \mathrm{P} 15-2$ & 22,01 & $2 \mathrm{P} 15-2$ & 27,28 & $2 \mathrm{P} 15-2$ & 26,97 \\
$3 \mathrm{P} 15-2$ & 13,64 & $3 \mathrm{P} 15-2$ & 14,70 & $3 \mathrm{P} 15-2$ & 15,80 & $3 \mathrm{P} 15-2$ & 11,59 \\
$4 \mathrm{P} 15-2$ & 14,19 & $4 \mathrm{P} 15-2$ & 16,19 & $4 \mathrm{P} 15-2$ & 17,45 & $4 \mathrm{P} 15-2$ & 16,87 \\
\hline
\end{tabular}

* Resultados que não puderam ser calculados pelo modelo, pois Tc > Tf

Pode-se observar que o modelo proposto por BUNGEY et al. [11], permite determinar a profundidade de fissura em $88.5 \%$ das medições realizadas. Nos $11.5 \%$ das medições restantes, a determinação das profundidades não foi possível, pois o tempo na região fissurada foi menor do que o tempo na região íntegra, o que inviabiliza, matematicamente, a aplicação do modelo. Inicialmente, será realizada uma análise da variância - ANOVA - para verificar se as médias dos resultados são consideradas diferentes em relação à distância de execução e às séries. A Tabela 3 apresenta o resultado desta análise.

Tabela 3: ANOVA da distância de execução em relação as séries.

\begin{tabular}{c|c|c|c|c|c}
\hline FATOR DE VARIAÇÃO & $\begin{array}{c}\text { GRAUS DE } \\
\text { LIBERDADE }\end{array}$ & $\begin{array}{c}\text { SOMA DE } \\
\text { QUADRADO }\end{array}$ & $\begin{array}{c}\text { QUADRADO } \\
\text { MÉDIO }\end{array}$ & ESTATíSTICA F & VALOR P \\
\hline Distância & 3 & 104,14 & 34,71 & 1,8392 & 0,1456 \\
\hline Séries & 2 & 1313,87 & 656,94 & 34,8065 & $<0,001$ \\
\hline $\begin{array}{c}\text { Interação } \\
\text { Série*Distância }\end{array}$ & 6 & 136,18 & 22,70 & 1,2025 & 0,3148 \\
\hline Resíduos & 73 & 1377,80 & 18,87 & & \\
\hline
\end{tabular}

Como o resultado da ANOVA indicou, através do valor $\mathrm{P}<0,001$, que existe diferença nos valores das profundidades entre as séries, será realizada a análise separada por série.

\subsection{Análise dos resultados - Série I}

Inicialmente será analisada o comportamento da dispersão dos dados desta série, apresentados na Tabela 4.

Tabela 4: Estatística descritiva variável distância (Série I).

\begin{tabular}{l|c|c|c|c}
\hline \multirow{2}{*}{ ESTATístICAS DOS RESULTADOS } & \multicolumn{4}{|c}{ SÉRIE I (5 cm) } \\
\cline { 2 - 5 } & \multicolumn{4}{|c}{ DISTÂNCIA Y } \\
\cline { 2 - 5 } & $\mathbf{1 0} \mathbf{~ c m}$ & $\mathbf{2 0} \mathbf{~ c m}$ & $\mathbf{3 0} \mathbf{~ c m}$ & $\mathbf{4 0} \mathbf{~ c m}$ \\
\hline Valor mínimo encontrado & 2,67 & 3,08 & 3,20 & 3,12 \\
\hline Valor máximo encontrado & 5,68 & 6,34 & 15,17 & 15,21 \\
\hline Média & 4,07 & 4,19 & 8,43 & 10,45 \\
\hline Mediana & 4,13 & 3,97 & 8,20 & 10,61 \\
\hline Variância & 1,04 & 1,24 & 13,26 & 14,53 \\
\hline Desvio padrão & 1,02 & 1,11 & 3,64 & 3,81 \\
\hline Coeficiente de variação & $25,03 \%$ & $26,53 \%$ & $43,18 \%$ & $36,48 \%$ \\
\hline Número de observações & 8 & 6 & 8 & 8 \\
\hline & & & &
\end{tabular}

Percebe-se que as distâncias de execução do ensaio de $10 \mathrm{~cm}$ e $20 \mathrm{~cm}$ apresentaram menores dispersões nos resultados, comprovadas pelos valores da variância, desvio-padrão e coeficiente de variação. Já as distâncias de $30 \mathrm{~cm}$ e $40 \mathrm{~cm}$ apresentaram uma maior dispersão.

A Figura 7 apresenta o Boxplot da Série I, considerando a variável distância de execução. Nela, é possível perceber a variabilidade dos dados para as distâncias maiores (30 e $40 \mathrm{~cm}$ ), e a menor variação para as distâncias de 10 e $20 \mathrm{~cm}$. 


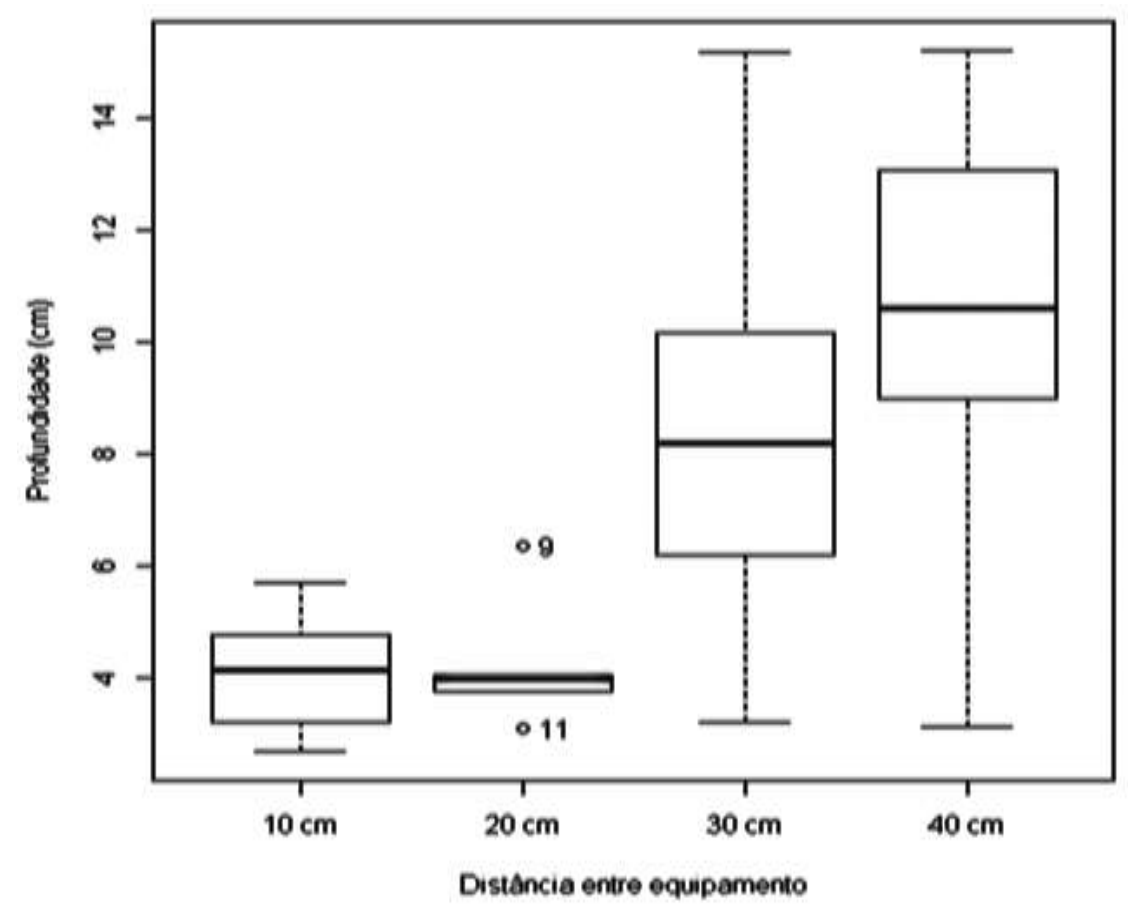

Figura 7: Boxplot variável: distância (Série I).

Para avaliar a influência da distância de execução do ensaio será realizado um teste de hipótese, análise da variância (ANOVA) e intervalo de confiança - I.C para constatar se há ou não diferenças entre os resultados de cada distância das séries. Para esta análise será adotada as seguintes hipóteses: Hipótese nula (H0), os tratamentos são iguais; Hipótese alternativa $(\mathrm{H} 1)$, pelo menos um difere dos demais. $\mathrm{O}$ valor $\mathrm{P}$ de corte é 0,05 .

As Tabelas 5 e 6 apresentam os resultados desta análise. Diante do valor P encontrado de 0,002 $(\mathrm{p}<0,05)$, rejeita-se a hipótese nula, e assim, os resultados podem ser considerados estatisticamente diferentes. Há evidências, portanto, que as distâncias de execução do ensaio diferem entre si para a Série I, são considerados estatisticamente iguais os resultados para as distâncias de 10 e $20 \mathrm{~cm}$ e os resultados de 30 e $40 \mathrm{~cm}$.

Tabela 5: ANOVA da profundidade $x$ distância (Série I).

\begin{tabular}{c|c|c|c|c|c}
\hline $\begin{array}{c}\text { FATOR DE } \\
\text { VARIAÇÃo }\end{array}$ & GRAUS DE LIBERDADE & $\begin{array}{c}\text { SOMA DE } \\
\text { QUADRADO }\end{array}$ & $\begin{array}{c}\text { QUADRADO } \\
\text { MÉDIO }\end{array}$ & ESTATíSTICA F & $\begin{array}{c}\text { VALOR } \\
\text { P }\end{array}$ \\
\hline Regressão & 3 & 227,8 & 75,95 & 9,496 & 0,0002 \\
\hline Resíduos & 26 & 207,9 & 8,00 & & \\
\hline
\end{tabular}

Tabela 6: Estatística comparativa entre as médias das profundidades x distância (Série I).

\begin{tabular}{c|c|c}
\hline DISTÂNCIAS DO EQUIPAMENTO & MÉDIA & ESTATÍSTICA COMPARATIVA \\
\hline $10 \mathrm{~cm}$ & 4,06 & $\mathrm{a}^{*}$ \\
\hline $20 \mathrm{~cm}$ & 4,19 & $\mathrm{a}$ \\
\hline $30 \mathrm{~cm}$ & 8,43 & $\mathrm{~b}$ \\
\hline $40 \mathrm{~cm}$ & 10,45 & $\mathrm{~b}$ \\
\hline
\end{tabular}

*Letras iguais nas linhas implica em igualdade de média

Aplicando o intervalo de confiança (I.C) com nível de confiança de 95\% resultou no intervalo apresentado na Tabela 7 para a Série I. 
Tabela 7: Intervalo de confiança da variável distância (Série I).

\begin{tabular}{c|c|c|c|c|c}
\hline SÉRIE & DISTÂNCIA Y & I.C & LIMITE INFERIOR & MÉDIA & LIMITE SUPERIOR \\
\hline \multirow{4}{*}{ Série I } & $10 \mathrm{~cm}$ & 0,85 & 3,21 & 4,07 & 4,92 \\
\cline { 2 - 6 } & $20 \mathrm{~cm}$ & 1,17 & 3,02 & 4,19 & 5,36 \\
\cline { 2 - 6 } & $30 \mathrm{~cm}$ & 3,04 & 5,39 & 8,43 & 11,48 \\
\cline { 2 - 6 } & $40 \mathrm{~cm}$ & 3,19 & 7,26 & 10,45 & 13,64 \\
\hline
\end{tabular}

A Figura 8 apresenta os gráficos do intervalo de confiança para Série I em relação às variáveis profundidade e distância.

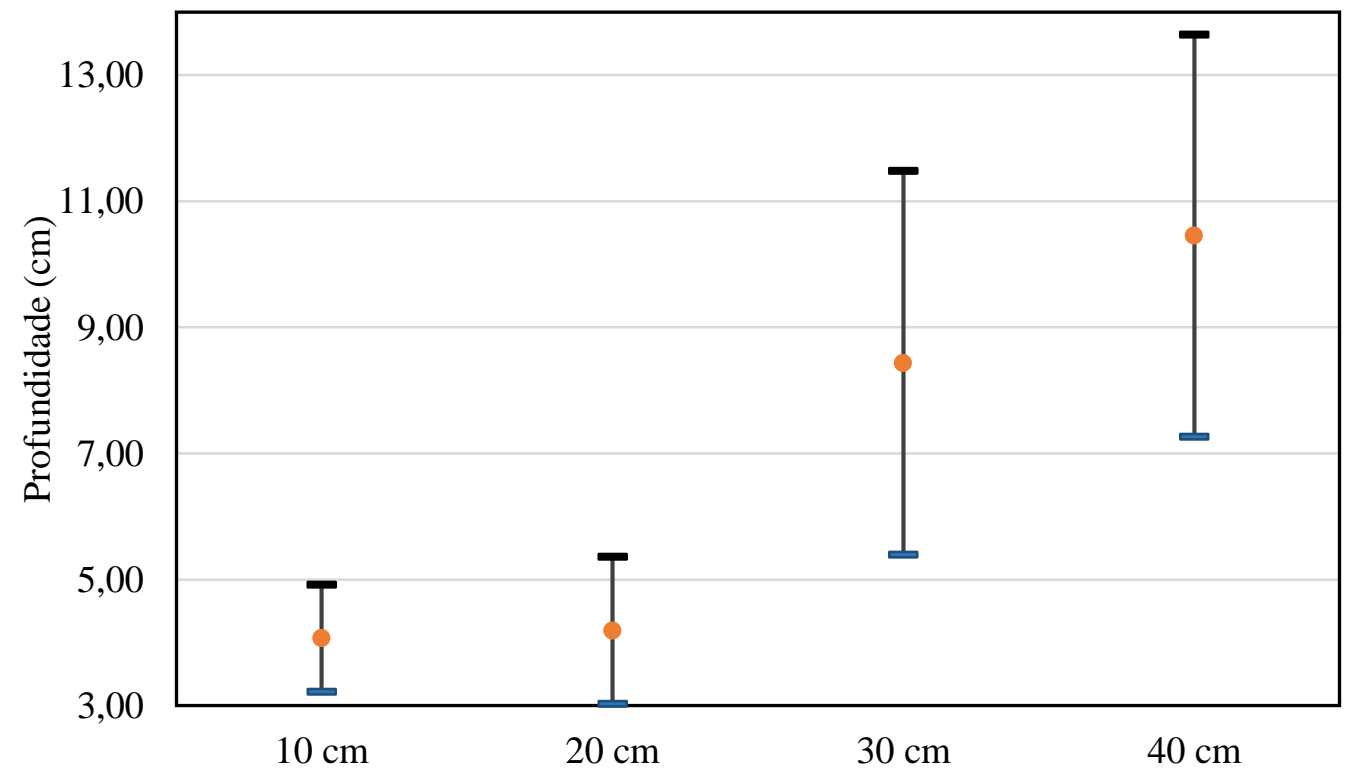

Série I

-Limite inferior - Média -Limite superior

Figura 8: Gráfico do intervalo de confiança (Variável profundidade x distância - Série I).

Aplicando a margem de erro considerada de $20 \%$, verifica-se que os resultados do I.C para a Série I, só podem ser considerados baixos para a distância de execução de $10 \mathrm{~cm}$, pois nesta distância a margem de erro representou $17 \%$ da medida real da profundidade, que é $5 \mathrm{~cm}$. Já para as distâncias de 20,30 e $40 \mathrm{~cm}$, os valores do I.C são considerados altos, pois as margens de erro representam, respectivamente, 23\%, $61 \%$ e $64 \%$ da medida real da profundidade de fissura. Apesar de o I.C da distância de $20 \mathrm{~cm}$ ter ultrapassado o limite de corte, que é $20 \%$, este conjunto de resultados conseguiu conter a medida real da profundidade de fissura dentro deste intervalo, sendo a margem de erro próxima do limite de corte.

\subsection{Análise dos resultados - Série II}

Inicialmente será analisada o comportamento da dispersão dos dados desta série, apresentados na Tabela 8.

Tabela 8: Estatística descritiva variável distância (Série II).

\begin{tabular}{c|c|c|c|c}
\hline \multirow{2}{*}{ ESTATíSTICAS DOS RESULTADOS } & \multicolumn{4}{|c}{ SÉRIE II (10 $\mathbf{~ c m ) ~}$} \\
\cline { 2 - 5 } & \multicolumn{4}{|c}{ DISTÂNCIA Y } \\
\cline { 2 - 5 } & $\mathbf{1 0} \mathbf{~ c m}$ & $\mathbf{2 0} \mathbf{~ c m}$ & $\mathbf{3 0} \mathbf{~ m}$ & $\mathbf{4 0} \mathbf{~ c m}$ \\
\hline Valor mínimo encontrado & 5,63 & 4,96 & 5,11 & 4,17 \\
\hline Valor máximo encontrado & 8,19 & 9,82 & 11,22 & 11,60 \\
\hline Média & 6,60 & 7,40 & 7,65 & 8,23 \\
\hline
\end{tabular}




\begin{tabular}{c|c|c|c|c}
\hline Mediana & 6,48 & 7,45 & 7,13 & 8,57 \\
\hline Variância & 0,59 & 3,54 & 6,74 & 10,34 \\
\hline Desvio padrão & 0,77 & 1,88 & 2,60 & 3,22 \\
\hline Coeficiente de variação & $11,67 \%$ & $25,46 \%$ & $33,96 \%$ & $39,09 \%$ \\
\hline Número de observações & 8 & 8 & 4 & 4 \\
\hline
\end{tabular}

Percebe-se que a distância de execução do ensaio de $10 \mathrm{~cm}$ apresentou menor dispersão nos resultados, fato comprovado pelos valores da variância, desvio-padrão e coeficiente de variação. Já as distâncias de 20 $\mathrm{cm}, 30 \mathrm{~cm}$ e $40 \mathrm{~cm}$ apresentaram uma maior dispersão. A Figura 9 apresenta o boxplot da Série II, considerando a variável distância de execução.

Analisando a Figura 9, é possível perceber a variabilidade dos dados para as distâncias maiores (20, 30 e $40 \mathrm{~cm}$ ), e menor variação para a distância de $10 \mathrm{~cm}$. Apesar de a distância de $20 \mathrm{~cm}$ ter apresentado maior variabilidade que a de $10 \mathrm{~cm}$, essa variação pode ser considerada aceitável diante dos resultados das demais distâncias.

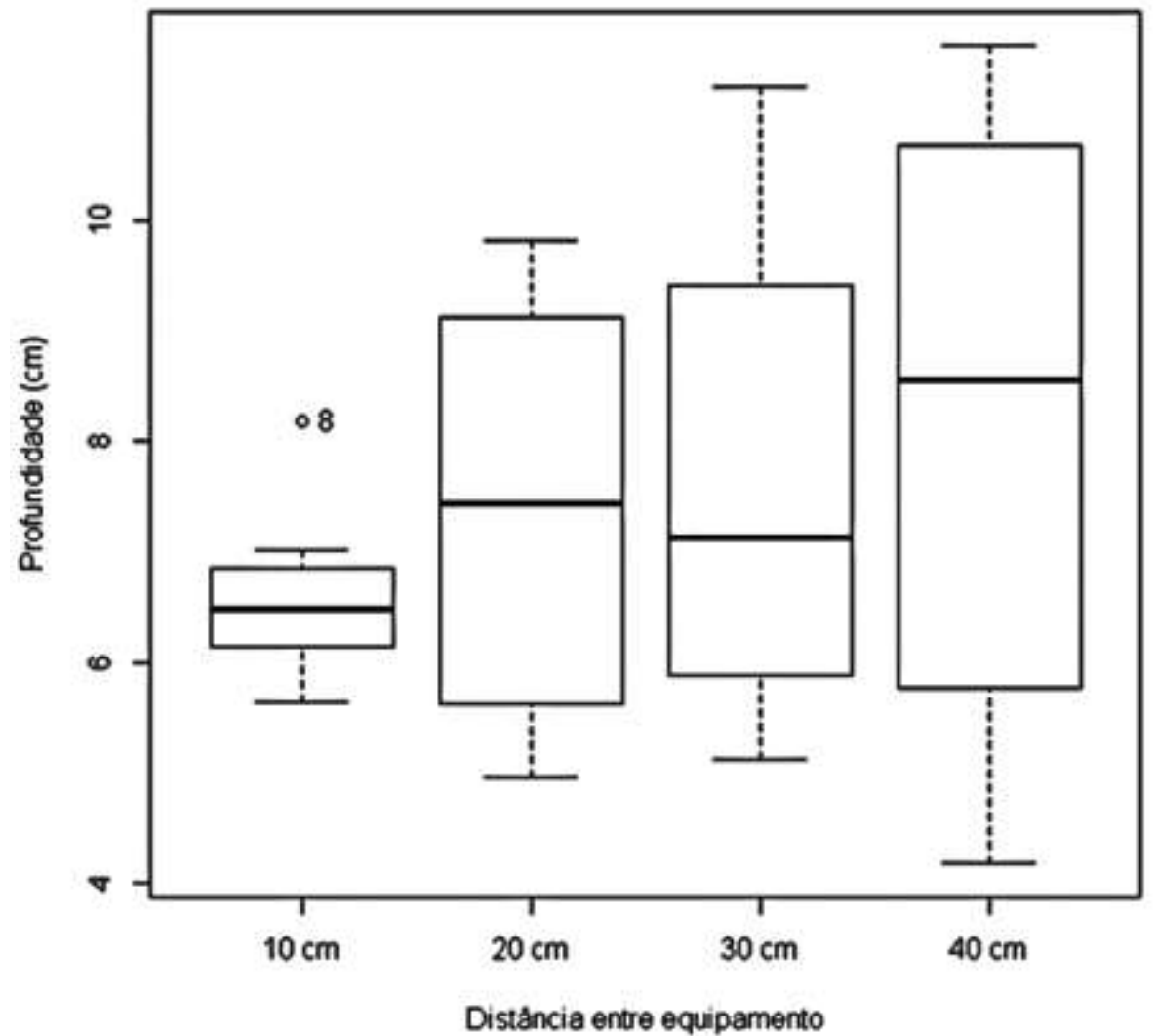

Figura 9: Boxplot variável: distância (Série II).

Para avaliar a influência da distância de execução do ensaio, será realizado um teste de hipótese, análise da variância (ANOVA) e intervalo de confiança - I.C - para constatar se há ou não diferenças entre os resultados de cada distância das séries. As Tabela 9 e 10 apresentam os resultados desta análise.

Tabela 9: ANOVA da profundidade x distância (Série II).

\begin{tabular}{c|c|c|c|c|c}
\hline FATOR DE VARIAÇÃo & $\begin{array}{c}\text { GRAUS DE } \\
\text { LIBERDADE }\end{array}$ & $\begin{array}{c}\text { SOMA DE } \\
\text { QUADRADO }\end{array}$ & $\begin{array}{c}\text { QUADRADO } \\
\text { MÉDIO }\end{array}$ & $\begin{array}{c}\text { ESTATÍSTICA } \\
\text { F }\end{array}$ & VALOR P \\
\hline Regressão & 3 & 7,93 & 2,644 & 0,659 & 0,587 \\
\hline Resíduos & 20 & 80,19 & 4,010 & & \\
\hline
\end{tabular}


Tabela 10: Estatística comparativa entre as médias das profundidades x distância (Série II).

\begin{tabular}{c|c|c}
\hline DISTÂNCIAS DO EQUIPAMENTO & MÉDIA & ESTATISTICA COMPARATIVA \\
\hline $10 \mathrm{~cm}$ & 6,60 & $\mathrm{a}^{*}$ \\
\hline $20 \mathrm{~cm}$ & 7,40 & $\mathrm{a}$ \\
\hline $30 \mathrm{~cm}$ & 7,65 & $\mathrm{a}$ \\
\hline $40 \mathrm{~cm}$ & 8,23 & $\mathrm{a}$ \\
\hline
\end{tabular}

*Letras iguais nas linhas implica em igualdade de média

Diante do valor $\mathrm{P}$ encontrado de 0,587 ( $\mathrm{p}>0,05)$, não se rejeita a hipótese nula, onde os resultados podem ser considerados estatisticamente iguais. Há evidências, portanto, que os resultados das distâncias de execução do ensaio são iguais entre si, para a Série II.

Aplicando o intervalo de confiança (I.C) com nível de confiança de 95\% resultou no intervalo apresentado na Tabela 11 para a Série II. A Figura 10 apresenta os gráficos do intervalo de confiança para Série II em relação a variável profundidade e distância.

Tabela 11: Intervalo de confiança da variável distância (Série II).

\begin{tabular}{c|c|c|c|c|c}
\hline SÉRIE & DISTÂNCIA Y & I.C & LIMITE INFERIOR & MÉDIA & LIMITE SUPERIOR \\
\hline \multirow{4}{*}{ Série II } & $10 \mathrm{~cm}$ & 0,64 & 5,95 & 6,60 & 7,24 \\
\cline { 2 - 6 } & $20 \mathrm{~cm}$ & 1,57 & 5,82 & 7,40 & 8,97 \\
\cline { 2 - 6 } & $30 \mathrm{~cm}$ & 4,13 & 3,51 & 7,65 & 11,78 \\
\cline { 2 - 6 } & $40 \mathrm{~cm}$ & 5,12 & 3,11 & 8,23 & 13,34 \\
\hline
\end{tabular}

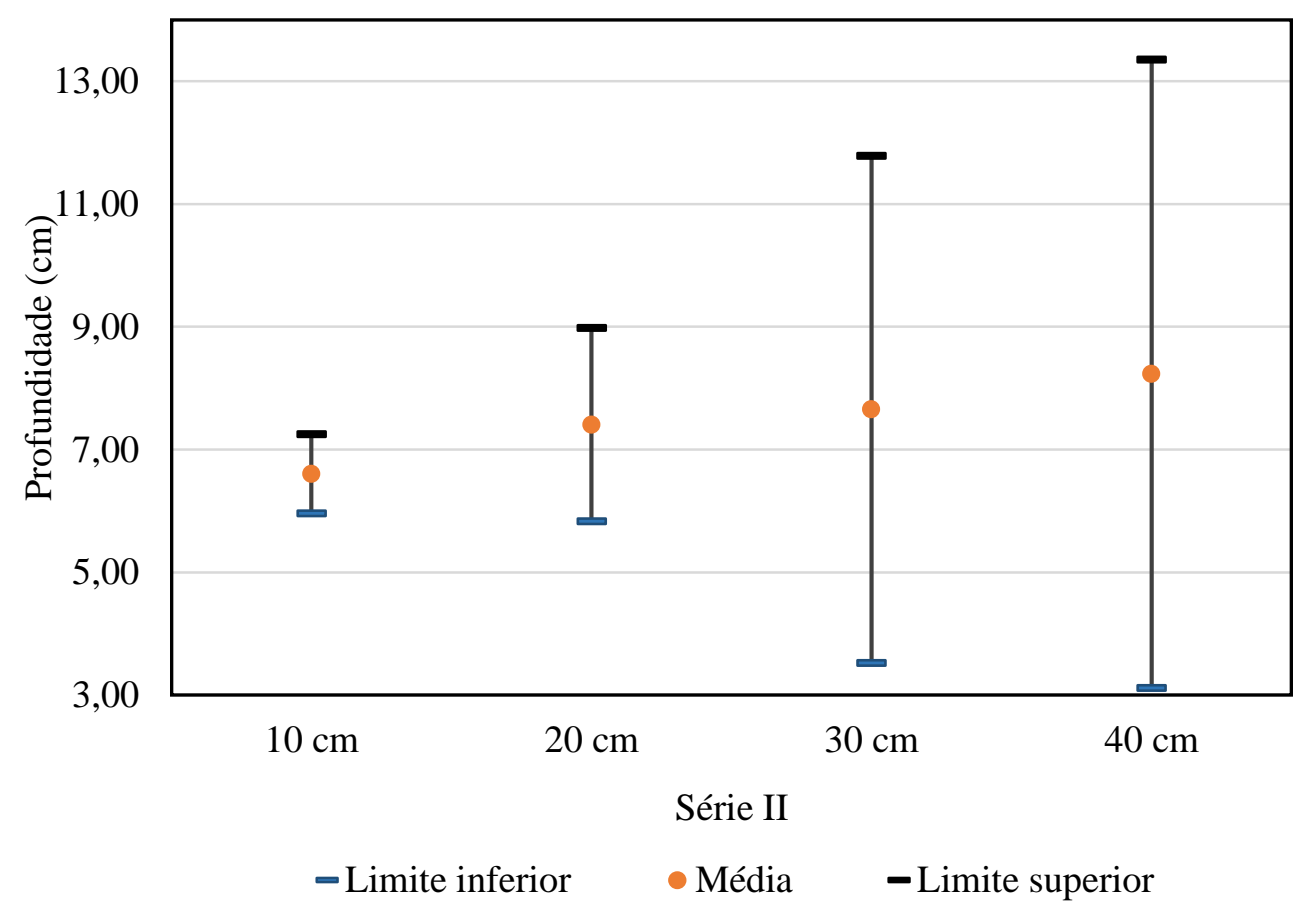

Figura 10: Gráfico do intervalo de confiança (Variável profundidade x distância - Série II).

Os resultados do I.C para Série II são considerados pequenos apenas para as distâncias de 10 e $20 \mathrm{~cm}$, pois o primeiro I.C representa uma variação de $6 \%$ em relação a profundidade real que é $10 \mathrm{~cm}$ e o segundo representa $15 \%$ de variação para esta medida. Já para as distâncias de 30 e $40 \mathrm{~cm}$ os valores são considerados altos pois representam respectivamente $41 \%$ e $51 \%$ de variação em relação a profundidade real.

Apesar de o I.C das distâncias de 10 e $20 \mathrm{~cm}$ terem sido menores, bem como as medidas de dispersão destes dados, as faixas de valores do intervalo de confiança não contém a medida da profundidade de fissura da Série II que é $10 \mathrm{~cm}$, comprometendo, desta forma a aplicação do modelo em estruturas reais. 


\subsection{Análise dos resultados - Série III}

Inicialmente será analisada o comportamento da dispersão dos dados desta série, apresentados na Tabela 12.

Tabela 12: Estatística descritiva variável distância (Série III).

\begin{tabular}{c|c|c|c|c}
\hline \multirow{2}{*}{ ESTATÍSTICAS DOS RESULTADOS } & \multicolumn{4}{|c}{ SÉRIE III (15 cm) } \\
\cline { 2 - 5 } & \multicolumn{4}{|c}{ DISTANCI Y } \\
\cline { 2 - 5 } & $\mathbf{1 0} \mathbf{~ c m}$ & $\mathbf{2 0} \mathbf{~ c m}$ & $\mathbf{3 0} \mathbf{~ c m}$ & $\mathbf{4 0} \mathbf{~ c m}$ \\
\hline Valor mínimo encontrado & 9,56 & 9,19 & 5,92 & 7,23 \\
\hline Valor máximo encontrado & 25,73 & 22,01 & 27,28 & 26,97 \\
\hline Média & 15,16 & 15,58 & 15,80 & 14,79 \\
\hline Mediana & 12,93 & 15,37 & 15,22 & 11,59 \\
\hline Variância & 39,90 & 15,81 & 52,71 & 55,12 \\
\hline Desvio padrão & 6,32 & 3,98 & 7,26 & 7,42 \\
\hline Coeficiente de variação & $41,67 \%$ & $25,51 \%$ & $45,95 \%$ & $50,19 \%$ \\
\hline Número de observações & 8 & 8 & 8 & 7 \\
\hline
\end{tabular}

Percebe-se que a distância de execução do ensaio de $20 \mathrm{~cm}$ apresentou menor dispersão nos resultados, comprovada pelos valores da variância, desvio-padrão e coeficiente de variação. Já as distâncias de 10, 30 e $40 \mathrm{~cm}$ apresentaram uma maior dispersão. A Figura 11 apresenta o boxplot da Série III, considerando a variável distância de execução.

Na Figura 11 é possível perceber a variabilidade dos dados para as distâncias de 10, 30 e 40 cm, já a distância de $20 \mathrm{~cm}$ apresentou menor variação.

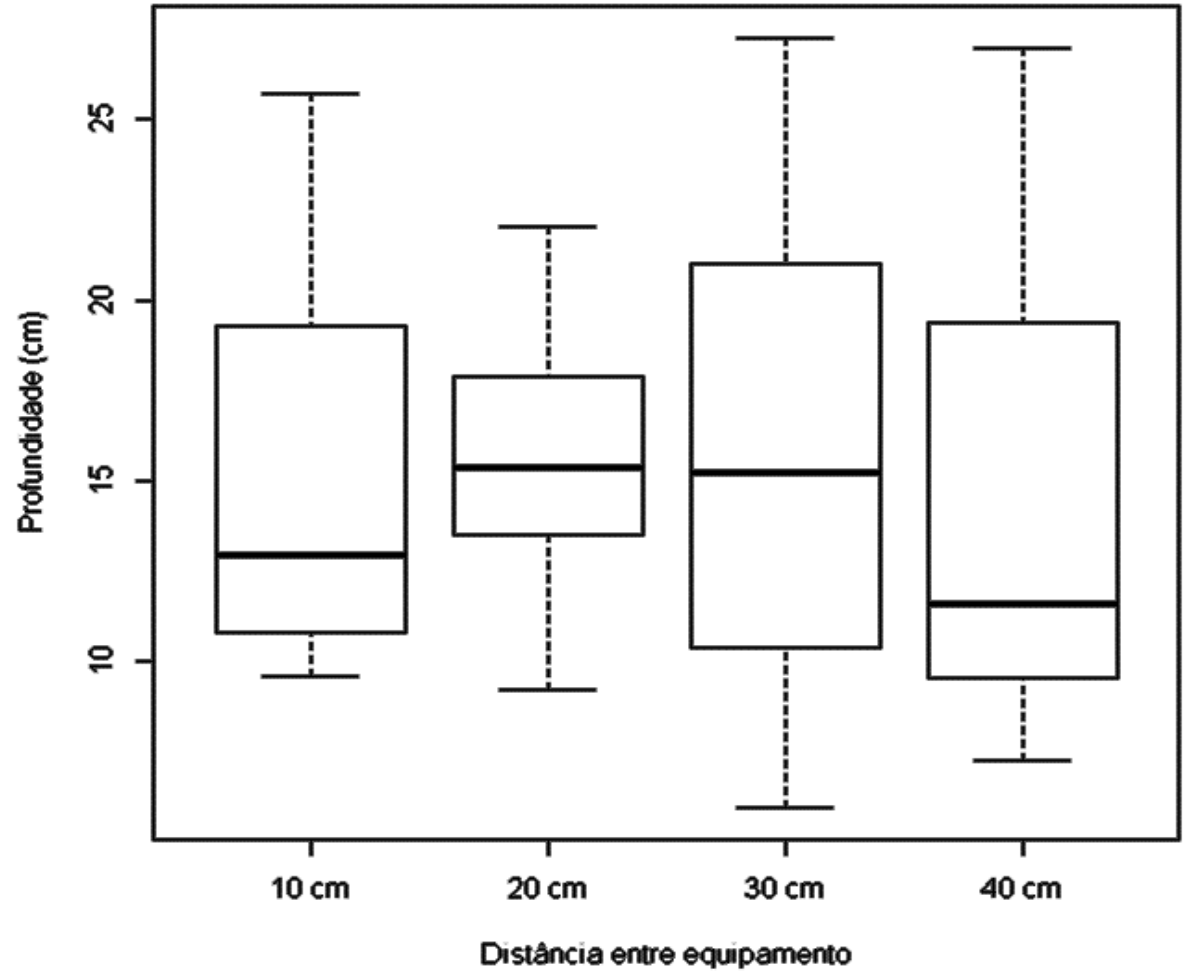

Figura 11: Boxplot variável: distância (Série III).

Os resultados da análise da variância constam nas Tabela 13 e 14. 
Tabela 13: ANOVA da profundidade $x$ distância (Série III).

\begin{tabular}{c|c|c|c|c|c}
\hline $\begin{array}{c}\text { FATOR DE } \\
\text { VARIAÇÃO }\end{array}$ & GRAUS DE LIBERDADE & $\begin{array}{c}\text { SOMA DE } \\
\text { QUADRADO }\end{array}$ & $\begin{array}{c}\text { QUADRADO } \\
\text { MÉDIO }\end{array}$ & $\begin{array}{c}\text { ESTATÍSTICA } \\
\mathbf{F}\end{array}$ & VALOR P \\
\hline Regressão & 3 & 4,5 & 1,52 & 0,038 & 0,99 \\
\hline Resíduos & 27 & 1089,7 & 40,36 & & \\
\hline
\end{tabular}

Tabela 14: Estatística comparativa entre as médias das profundidades $x$ distância (Série II).

\begin{tabular}{c|c|c}
\hline DISTÄNCIAS DO EQUIPAMENTO & MÉDIA & ESTATISTICA COMPARATIVA \\
\hline $10 \mathrm{~cm}$ & 15,16 & $\mathrm{a}^{*}$ \\
\hline $20 \mathrm{~cm}$ & 15,58 & $\mathrm{a}$ \\
\hline $30 \mathrm{~cm}$ & 15,80 & $\mathrm{a}$ \\
\hline $40 \mathrm{~cm}$ & 14,79 & $\mathrm{a}$ \\
\hline
\end{tabular}

*Letras iguais nas linhas implica em igualdade de média

Diante do valor P encontrado de 0,99 (p>0,05), não se rejeita a hipótese nula, na qual os resultados podem ser considerados estatisticamente iguais. Há evidências, desta forma, que as distâncias de execução do ensaio não diferem entre si, para a Série III.

Aplicando o intervalo de confiança (I.C) com nível de confiança de $95 \%$ resultou no intervalo apresentado na Tabela 15 para a Série III. A Figura 12 apresenta os gráficos do intervalo de confiança para Série III em relação a variável profundidade e distância.

Tabela 15: Intervalo de confiança da variável distância (Série III).

\begin{tabular}{c|c|c|c|c|c}
\hline SÉRIE & DISTÂNCIA Y & I.C & LIMITE INFERIOR & MÉDIA & LIMITE SUPERIOR \\
\hline \multirow{4}{*}{ Série III } & $10 \mathrm{~cm}$ & 5,28 & 9,88 & 15,16 & 20,44 \\
\cline { 2 - 6 } & $20 \mathrm{~cm}$ & 3,32 & 12,26 & 15,58 & 18,91 \\
\cline { 2 - 6 } & $30 \mathrm{~cm}$ & 6,07 & 9,73 & 15,80 & 21,87 \\
\cline { 2 - 6 } & $40 \mathrm{~cm}$ & 6,87 & 7,92 & 14,79 & 21,66 \\
\hline
\end{tabular}

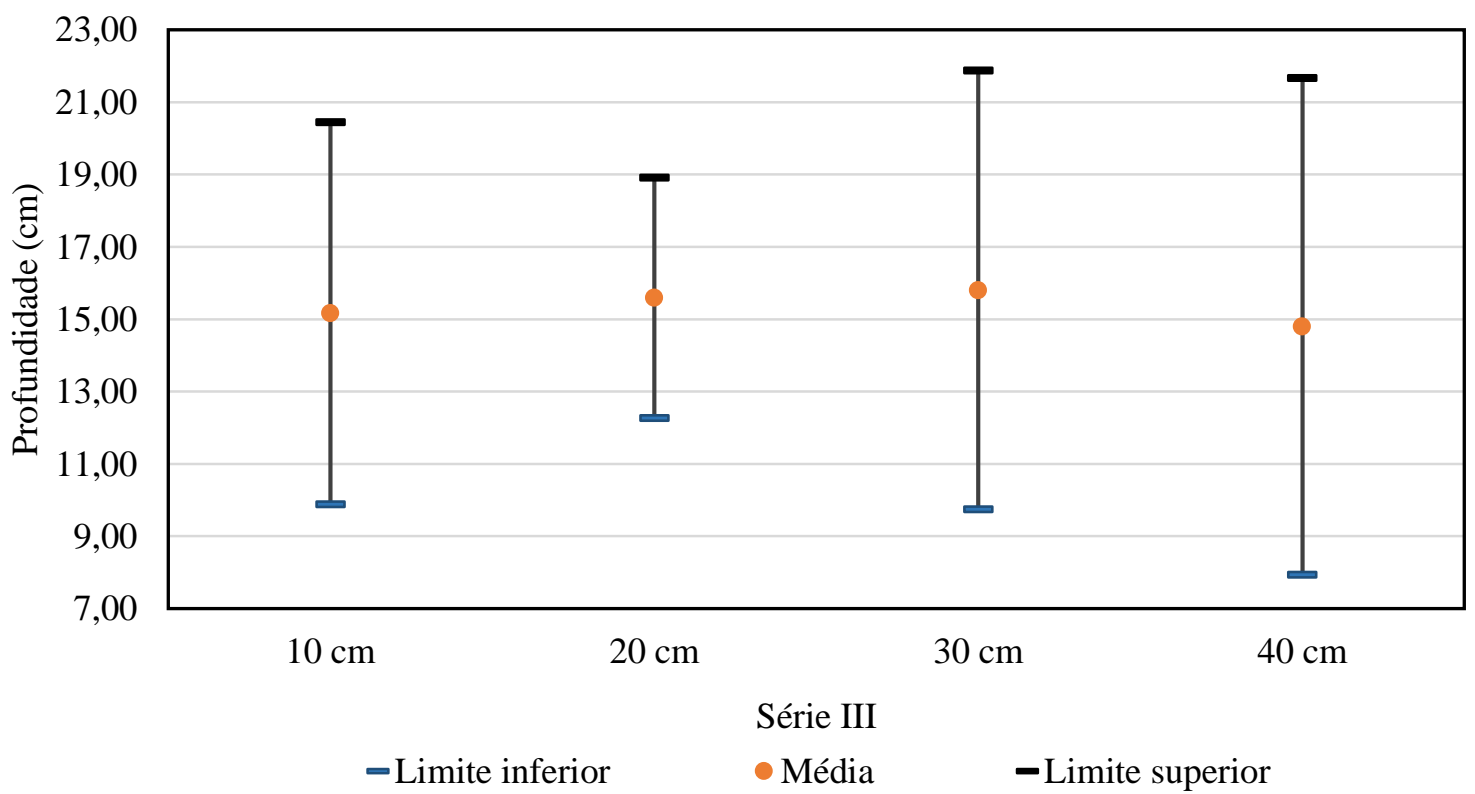

Figura 12: Gráfico do intervalo de confiança (Variável profundidade x distância - Série III)

Aplicando a margem de erro considerada de $20 \%$, verifica-se que os resultados do I.C para Série III apresentam-se todos acima desta margem. Os valores de I.C encontrados para as distâncias de 10, 20, 30 e 40 $\mathrm{cm}$ representam, respectivamente, 35\%, 22\%, 40\% e 46\% em relação à profundidade real, que é $15 \mathrm{~cm}$. Desta forma, a distância de $20 \mathrm{~cm}$, apesar de ter ultrapassado a margem de corte, ficou próximo desta e apresentou também menor dispersão dentre as demais. 
Da análise estatística da variável distância de execução do ensaio, a média dos resultados das diferentes distâncias podem ser consideradas estatisticamente iguais, havendo apenas na Série I diferença estatística. Apesar desta constatação, percebe-se que com o aumento da distância de execução do ensaio, os resultados se tornam mais variáveis e mais dispersos, sendo que para distâncias de até $20 \mathrm{~cm}$ os resultados apresentam menor variabilidade.

Percebe-se também que nas distâncias de 10 e $20 \mathrm{~cm}$, onde os dados estão menos variáveis e com intervalos de confiança menores, a medida real da profundidade não se encontra dentro da faixa dos limites do I.C, e que normalmente a medida real da profundidade só se encaixa dentro da faixa quando as margens de erros são maiores, o que inviabilizaria a aplicação do modelo.

Mesmo obtendo-se os resultados com a aplicação do modelo de BUNGEY et al. [11], os valores encontrados foram muito dispersos e apresentaram, em sua maioria, uma margem de erro elevada, fato que também foi percebido nas pesquisas de MEDEIROS [12] e SOUZA [13].

Atribui-se esta variabilidade dos resultados ao fato de ser o concreto um material heterogêneo e que a velocidade de propagação da onda pode variar, apesar do modelo adotar como premissa a velocidade constante na região íntegra. Outro ponto relevante é em relação ao caminho da onda, pois o modelo adota apenas um caminho possível, porém o percurso é incerto, podendo ser diferente do adotado.

\section{CONCLUSÕES}

No presente trabalho foi realizado um estudo experimental para avaliar a estimação de fissuras em concreto através do método de ultrassom. Para o qual foram moldados prismas de concreto com três diferentes profundidades, realizando o ensaio a diferentes distâncias de execução para observar a influência deste parâmetro na estimação. Diante dos resultados apresentados e da análise dos mesmos, percebe-se que o ensaio de ultrassom é sensível e eficaz para detectar a presença de fissuras no concreto. Afinal, o tempo de propagação da onda é alterado na presença de fissuras, apresentando valor maior do que o observado na região íntegra do concreto

Quanto ao modelo encontrado na literatura para estimação de profundidade de fissuras, foi possível determinar a profundidade na maior parte das medições realizadas. No entanto, existe uma porcentagem no qual não foi possível, porque o tempo na região fissurada foi menor do que o tempo na região íntegra, fato que pode ser devido ao percurso da onda diferente do previsto, bem como a heterogeneidade do material.

Referente as distâncias de execução do ensaio até $20 \mathrm{~cm}$ apresentam menor variabilidade, enquanto para as distâncias de 30 e $40 \mathrm{~cm}$ os resultados se apresentaram muito dispersos.

A aplicação do modelo matemático para estimar profundidade de fissuras em concreto com o uso do ultrassom apresenta uma margem de erro elevada, podendo comprometer a aplicação em estruturas reais.

\section{BIBLIOGRAFIA}

[1] SANTOS, R.C., "Concreteiras aumentam participação na construção civil”, Revista M\&T manutenção $e$ tecnologia, n. 173, pp. 12-16, Out. 2013.

[2] SAHUINCO, M.H., "Utilização de métodos não destrutivos e semi-destruitivos na avaliação de pontes de concreto”, Dissertação de M.Sc., Escola Politécnica, Universidade de São Paulo, São Paulo. 2011.

[3] SILVA FILHO, L.C.P., HELENE, P., “Análise de estruturas de concreto com problemas de resistência e fissuração”, In: Concreto: Ciência e Tecnologia, v. 2, São Paulo: Editora IBRACON, pp. 1124-1174, 2011.

[4] AGGELIS, D.G., KORDATOS, E.Z., SOULIOTI, D.V., et al., "Combined use of thermography and ultrasound for the characterization of subsurface cracks in concrete", Construction and Building Materials, v. 24, n. 10, pp. 1888-1897, 2010.

[5] LORENZI, A., REGINATO, L.A., LORENZI, L.S., et al., "Emprego de ensaios não destrutivos para inspeção de estruturas de concreto", Revista de Engenharia Civil IMED, v. 3, n.1, pp. 3-13, 2016.

[6] MARAN, A.P., BARRETO, M.F., ROHDEN, A.B., et al., "Análise da espessura do cobrimento de armadura em lajes com diferentes distanciamentos entre espaçadores e pontos de amarração", Revista IBRACON de Estruturas e Materiais, v. 8, n. 5, pp. 625-643, Out. 2015.

[7] TOMAZELI, A., "Diretrizes para a inspeção, análise e aceitação de superestruturas em concreto armado de edifícios habitacionais com obras paralisadas”, Dissertação de M.Sc., Instituto de Pesquisa Tecnológicas do Estado de São Paulo, São Paulo, 2017.

[8] CÁNOVAS, M.F., Patologia e terapia do concreto armado, 1. ed., São Paulo, PINI, 1988. 
[9] PACHECO, J., BILESKY, P., MORAIS, T., et al., "Considerações sobre o Módulo de Elasticidade do concreto", In: Congresso Brasileiro Do Concreto, 56, Natal, 2014.

[10] MENEZES, V.S., FERRONATO, D.N., SANTOS, E.M., et al., "Estudo do comportamento da porosidade de pasta de cimento por ultrassom", In: Congresso Brasileiro De Cerâmica, 60, Águas de Lindóia, 2016.

[11] BUNGEY, J.H., MILlARD, S.G., GRANTHAM, M.G., Testing of concrete in structures, 4 ed., Oxon, Taylor \& Francis, 2006.

[12] MEDEIROS, A., "Aplicação do ultra-som na estimativa da profundidade de fendas superficiais e na avaliação da eficácia de injeções em elementos de concreto armado", Dissertação de M.Sc., Universidade Federal de Santa Catarina, Florianópolis, 2007.

[13] SOUZA, G.B., “Avaliação do método de propagação de onda ultrassônica na determinação da profundidade de fissura em concreto”, Dissertação de M.Sc., Universidade Católica de Pernambuco, Recife, 2016.

[14] CONTROLS GROUP, Catálogo técnico do medidor de pulso ultrassônico, http://www.controlsgroup.com/eng/concrete-testing-equipment/ultrasonic-pulse-velocity-tester.php. Acessado em setembro de 2018.

[15] American Society for Testing and Materials, C595 / C595M-17: Standard Specification for Blended Hydraulic Cements, ASTM International, West Conshohocken, PA, 2017.

[16] Associação Brasileira de Normas Técnicas, NBR 7211: Agregados para concreto - especificação. Rio de Janeiro, 2009.

[17] HAIR, J.F., Análise Multivariada de Dados, 6. ed., Porto Alegre, Bookman, 2009.

[18] Associação Brasileira de Normas Técnicas, NM 58: Concreto endurecido - Determinação da velocidade de propagação de onda ultrassônica. Rio de Janeiro, 1996.

[19] Associação Brasileira de Normas Técnicas, NBR 8802: Concreto endurecido - Determinação da velocidade de propagação de onda ultrassônica. Rio de Janeiro, 2013.

\section{ORCID}

Marcela Tavares de Araújo Silva Joaquin Humberto Aquino Rocha Eliana Cristina Barreto Monteiro https://orcid.org/0000-0001-6590-5044

https://orcid.org/0000-0002-3383-6379

https://orcid.org/0000-0003-0842-779X 